\title{
Pain-Relieving Effect of Music on Preschoolers during Immunization: A Randomized Controlled Trial
}

\author{
Yui Shiroshita', Kotaro Muraki², Tatsuya Kamei', Ikuko Sobue ${ }^{1}$ \\ ${ }^{1}$ Division of Nursing Science, Graduate School of Biomedical \& Health Sciences, Hiroshima University, Hiroshima, Japan \\ ${ }^{2}$ Muraki Pediatric Clinic, Hiroshima, Japan \\ Email: d176710@hiroshima-u.ac.jp
}

How to cite this paper: Shiroshita, Y., Muraki, K., Kamei, T. and Sobue, I. (2018) Pain-Relieving Effect of Music on Preschoolers during Immunization: A Randomized Controlled Trial. Health, 10, 145-158.

https://doi.org/10.4236/health.2018.101012

Received: December 27, 2017

Accepted: January 27, 2018

Published: January 30, 2018

Copyright $\odot 2018$ by authors and Scientific Research Publishing Inc. This work is licensed under the Creative Commons Attribution International License (CC BY 4.0).

http://creativecommons.org/licenses/by/4.0/

c. (i) Open Access

\begin{abstract}
Background: Immunization is a medical procedure many children frequently undergo. As it involves pain, it is important to develop effective pain relief methods that are applicable from infancy. Objective: To clarify the pain-relieving effect of music from speakers on preschoolers during immunization. Methods: A randomized controlled trial using sex-based stratified randomization was conducted at a Japanese pediatric clinic between October and December 2016, involving 48 preschoolers aged 5 - 6. Among these, 25 listened to music ("Twinkle Twinkle Little Star" played by a music box) from speakers before, during, and after influenza immunization (Music group), while the other 23 were not treated with musical intervention (Control group), with the following outcomes: primary: the Face Scale score; and secondary: the heart rate (HR) and oxygen saturation $\left(\mathrm{SpO}_{2}\right)$ and salivary alpha amylase (sAA) levels. Results: The Face Scale score and HR of the Control group immediately after influenza immunization were significantly higher than their baseline values $(\mathrm{P}<0.0001, \mathrm{P}<0.05)$. There were no significant differences between the Music and Control groups in the Face Scale score, $\mathrm{HR}$, or $\mathrm{SpO}_{2}$ level immediately after influenza immunization or in the sAA level 10 minutes after it. Conclusion: Influenza immunization was painful for preschoolers. When based on the Face Scale score, $\mathrm{HR}, \mathrm{SpO}_{2}$ and sAA levels as indices to measure immunization-related pain, music did not show pain-relieving effects.
\end{abstract}

\section{Keywords}

Pain, Immunization, Music, Preschoolers 


\section{Introduction}

Immunization is a medical procedure many children frequently undergo. Before reaching the age of 6 , they receive 20 or more immunizations, including polio, BCG, measles, and rubella vaccines, in Japan [1] [2]. As each immunization involves pain [3], insufficient pain management may result in future medical fear or pain [4]. Therefore, it is important to develop effective methods to reduce pain during immunization.

Methods to reduce immunization-related pain in children are classified into pharmacological and non-pharmacological approaches [5] [6] [7]. The latter include: musical interventions [5] [8], distraction using videos [5] [8], breathing techniques [5] [9], sucrose administration [8] [10], and positioning [10]. In a systematic review to examine the pain-relieving effect of music, it was shown to reduce pain and anxiety in children (aged 1 - 18) when receiving medical care [11]. Music also shows pain-relieving effects in heel lance for infants [12], as well as blood sampling [13] [14] [15] and acupuncture [16] for preschoolers and school-age children. Another systematic review examined various distraction techniques to address immunization-related pain in children, and similarly confirmed the pain-relieving effect of music on children aged 3 - 7 [5]. Such an effect was also reported in studies involving infants [17], infants and preschoolers [18], preschoolers [19], and adolescents [20].

Musical interventions for children include: listening to music through heador earphones, active music therapy, and listening to music from speakers. Among these, listening to music through head- or earphones has been reported to reduce pain in children, including preschoolers, when receiving medical care (immunizations, blood sampling, and acupuncture) [14] [16] [19]. However, with respect to immunization-related pain, Fowler-Kerry examined 200 children aged $4-6$, and reported the effectiveness of combined suggestion-musical interventions [19]. In other previous studies involving preschoolers aged 3 - 6, such pain was not reduced by listening to music through head- or earphones [21] [22]. In the case of musical interventions using head or earphones, it should be noted that children may miss to listen to medical professionals' instructions.

In contrast, active music therapy performed by music therapists has been shown to be effective to reduce pain in children, including preschoolers, when receiving medical care (immunization and blood sampling) [15] [18]. On the other hand, in Japan, the number of music therapists is very small, and their range of activity is limited to psychology, psychosomatic medicine, and rehabilitation [23]. They generally perform music therapy for purposes other than pain relief in the clinical setting, and, to the authors' knowledge, there have been no studies addressing this issue in the research field.

In a previous study involving children, including preschoolers and school-age children, musical intervention using speakers effectively reduced pain due to blood sampling [13]. In another study involving 118 children aged $13-15$, the effect of music to reduce immunization-related pain was higher when listening 
to it without headphones than when listening to it with headphones [20]. However, to the authors' knowledge, there have been no studies examining the effect of music from speakers to reduce immunization-related pain in children, including preschoolers. In order to develop safe and generalizable pain relief methods for preschoolers who frequently receive immunizations, it may be useful to clarify the effect of such music to reduce their immunization-related pain.

This exploratory study examined the pain-relieving effect of music from speakers on preschoolers during immunization, based on the following hypotheses: 1) Immunization is less painful for preschoolers treated with than those not treated with musical intervention; and 2) Immunization is less stressful for preschoolers treated with than those not treated with musical intervention.

\section{Methods}

\subsection{Design}

A randomized controlled trial. Based on the findings of a previous study examining differences in subjective pain perception between male and female children [24], sex-based stratified randomization was performed. Using a table of random sampling numbers, the researchers randomized subjects into Music and Control groups in the order of reservation.

The study was approved by the Ethics Committee of Hiroshima University (approval number: C-103) and registered with the UMIN Clinical Trials Registry (UMIN000023582). It conforms to the CONSORT guidelines for the reporting of randomized controlled trials.

The subjects' assent was obtained from their parents as their legal representatives. When the parents of candidate children made reservations for an influenza immunization by telephone, staff of the collaborative study facility explained the study objective to them, and confirmed their children's intention to participate. To the parents of those who assented to participate in the study, explanatory documents outlining the study for parents and children, informed assent and assent cancellation forms, and a questionnaire regarding immunizations for children (the numbers of past NICU admissions and surgeries) were mailed or directly handed over by staff of the collaborative study facility. On the day of immunization, the researchers provided sufficient written and oral explanations of the study to obtain written assent from the parents. The children were also provided with explanation using a picture book to obtain their oral assent.

\subsection{Sampling and Settings}

The subjects were recruited at A clinic in Hiroshima from 9:00 to 18:00 each day during the period between October and December 2016. The inclusion and exclusion criteria were as follows: inclusion: (1) preschoolers aged 5 or 6 and scheduled only for an influenza immunization, and (2) those approved for the immunization by the physician in charge; and exclusion: (1) those with a history of treatment using analgesics, (2) those with auditory or visual impairment, (3) 
those with intellectual or developmental impairment, and (4) those regarded as inappropriate for the study by the physician in charge.

When determining the sample size, a study conducted by Ogawa et al., involving 32 children [25], was referred to. This previous study compared the children's dental treatment-related stress based on their sAA levels, and revealed significant decreases in such levels after treatment. Considering that a comparison of sAA levels similar to this would be feasible using controls, the size of each group was set at 50 in the present study.

\subsection{Measures}

The sex and age were used as demographic variables, and the following items were used as confounders: the numbers of past NICU admissions, hospitalizations, surgeries, immunizations, injections, influenza vaccinations during this season, and elder and younger siblings who attended; minimum and maximum sound levels in the treatment and waiting rooms; room temperature and humidity; and the time to initiate the study, period from the initiation to immunization, and duration.

The primary outcome variable was the Face Scale score. The Face Scale developed by Wong-Baker shows a series of faces expressing 6 different levels of pain from <no pain> (0) to <extreme pain> (5) [26]. The scale has been shown to have sufficient reliability and validity [27]. Its Japanese version has also been proven to have sufficient concurrent validity and reliability based on re-test results [28]. The guidelines for the assessment of acute pain in children [29] recommend the use of the scale from the age of 3 . It is particularly frequently used in pediatrics [26], such as pain assessment for children during blood sampling [15] [30].

The secondary outcome variables were: the heart rate (HR) and oxygen saturation $\left(\mathrm{SpO}_{2}\right)$ and salivary alpha amylase (sAA) levels. The $\mathrm{HR}$ and $\mathrm{SpO}_{2}$ level are used as indices to assess pain in children undergoing painful medical procedures, as they were shown to markedly increase after immunization, blood sampling, or acupuncture in previous studies [13] [16] [21] [31]. The sAA level that increases with stress [32] is used for stress assessment for children undergoing blood sampling [30] or receiving dental treatment [25].

\subsection{Procedures}

\subsubsection{Music Group}

For each child and his/her mother, an approximately 15-minute intervention session was held in a private room from 5 minutes before to 10 minutes after immunization (Figure 1).

During the intervention, a CD that contains 'Twinkle Twinkle Little Star' played in an orgel sound (Dreaming Orgel Best, KICG 422, King Record) was used. The music, which is familiar to children aged 6 or younger [33], effectively reduced immunization-related pain and distress in previous studies involving infants aged 2 months and preschoolers aged 4 - 6, respectively [17] [34]. Without 


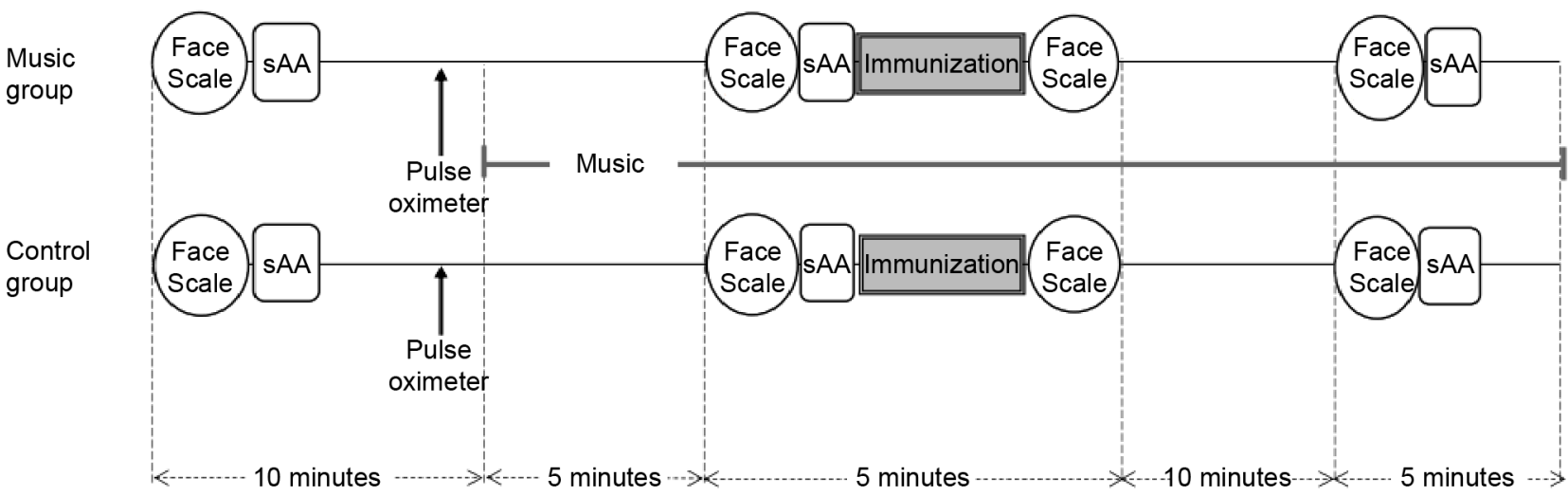

Figure 1. Flow diagram.

changes in the volume, tempo, or rhythm, orgel sounds meet the requirements of music therapy for children defined in the guidelines [35]. In the present study, the CD was played using a CD player (CD Radio TY-C24(W), TOSHIBA Lifestyle Electronics Trading Co., Ltd.). Based on the guidelines on music therapy for children [35], a sound level of $60-80 \mathrm{~dB}$ at frequency-weighting grade $\mathrm{C}$ was maintained using a sound level meter (Standard Sound Level Meter NL-21, LION Co., Ltd.) when playing the music. The CD player was placed at a distance of $150 \mathrm{~cm}$ from the child.

To create an environment similar to those for care in the clinical setting, each child was allowed to freely play using toys within the room from admission to the end of intervention. With the child's assent, his/her baseline Face Scale score and sAA level (Salivary Amylase Monitor 27B1X00045000110, Nipro Corporation/NS Materials Inc.) were measured. With a pulse oximeter (New Radical-7, 22200BZX00798000, Masimo Japan Co., Ltd.) attached to his/her right thumb, $\mathrm{HR}$ and $\mathrm{SpO}_{2}$ measurements were performed 33 times at intervals of 30 seconds until 10 minutes after immunization. From 1 minute after the initiation of measurement, the music was played through the $\mathrm{CD}$ speaker in the room. At 5 minutes after the initiation of music reproduction (6 minutes after the initiation of measurement), the Face Scale score and sAA level were measured. Subsequently, a physician and nurse entered the private room, and the former inserted a 27G needle (FN Syringe, 22100BZX00909, Terumo Corporation) into the child's left upper arm to administer an influenza vaccine of $0.5 \mathrm{~mL}$. The maximum $\mathrm{HR}$ and minimum $\mathrm{SpO}_{2}$ level during the period from needle insertion to 30 seconds after it were adopted as measurement values. Immediately after immunization, the Face Scale score was also measured. For the subsequent 10 minutes, the child freely played using toys within the room. At 10 minutes after immunization, Face Scale score and sAA measurements were performed again. Musical intervention ended after the removal of the pulse oximeter. The parent accompanied the child throughout the intervention.

\subsubsection{Control Group}

For the Control group, musical intervention was not provided, but immuniza- 
tion and Face Scale score, sAA, HR, and $\mathrm{SpO}_{2}$ measurements were performed, similarly to the Music group.

\subsection{Statistical Analysis}

The demographic variables, confounders, Face Scale score, HR, and sAA level were compared between the Music and Control groups. The categorical variables were examined using Fisher's exact test, while the continuous variables were analyzed using the Wilcoxon rank sum test or unpaired t-test based on the results of the Shapiro-Wilk test.

Among the results obtained through 30 repetitions of measurement at intervals of 2 seconds for 1 minute immediately after pulse oximeter attachment, the maximum $\mathrm{HR}$ and minimum $\mathrm{SpO}_{2}$ level were adopted as baseline values. In addition, the maximum $\mathrm{HR}$ and minimum $\mathrm{SpO}_{2}$ level obtained through 15 repetitions of measurement at intervals of 2 seconds for 30 seconds during the period from 1 minute after pulse oximeter attachment to 10 minutes after immunization were adopted as subsequent values [36].

To examine the changes of the sAA level or Face Scale score between baseline and each of time point, the paired t-test or signed rank sum test was conducted based on the Shapiro-Wilk test results, and the Bonferroni correction was performed. Furthermore, the $\mathrm{HR}$ and $\mathrm{SpO}_{2}$ level were compared using one-way analysis of variance (Dunnett test). For analysis, the statistical software SAS9.4 was used.

\section{Results}

Informed assent was obtained from 48 (Music: 25 and Control: 23) preschoolers (Figure 2). There were no significant differences between the 2 groups in the age or sex (Table 1). Among the confounders, only the rate of having a history of NICU admission was significantly higher in the Control $(4 ; 17.39 \%)$ compared with Music (0;0\%) group $(\mathrm{P}=0.0455)$ (Table 1$)$.

\subsection{Comparison between the Music and Control Groups}

There were no significant differences between the groups in the Face Scale score, HR, or sAA level at the baseline (Figure 3, Figure 4 and Figure 5). As the Control group showed a significantly higher baseline $\mathrm{SpO}_{2}$ level $(\mathrm{P}=0.0297)$, analysis of covariance was used to adjust the value for comparison between them (Figure 6).

At the 12 points from 1 minute after the initiation of measurement to immediately before immunization, there were no significant differences between the Music and Control groups in the $\mathrm{HR}$ or $\mathrm{SpO}_{2}$ level. Similarly, there were no significant differences between them in the Face Scale score or sAA level at 5 minutes after the initiation of musical intervention ( 6 minutes after the initiation of measurement in the Control group).

None of the 3 items, the Face Scale score, $\mathrm{HR}$, and $\mathrm{SpO}_{2}$ level, markedly varied 


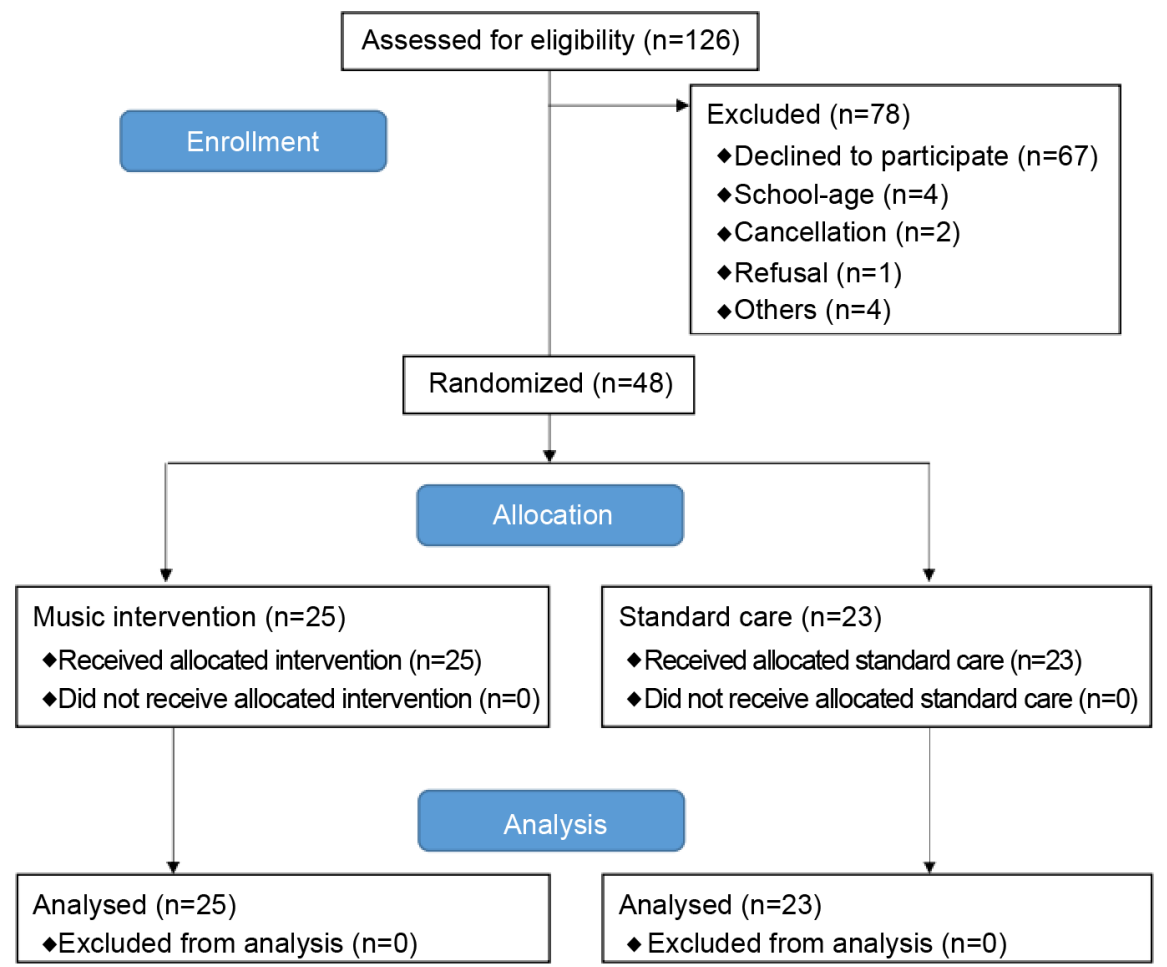

Figure 2. Flowchart of participant recruitment according to CONSORT 2010 guidelines.

Table 1. Demographic variables and confounding variables $\mathrm{N}=48$.

\begin{tabular}{|c|c|c|c|c|c|}
\hline \multirow[t]{2}{*}{ Variable (unit) } & \multicolumn{2}{|c|}{ Music group $(n=25)$} & \multicolumn{2}{|c|}{ Control group $(n=23)$} & \multirow[t]{2}{*}{$P$-value } \\
\hline & Mean & SD & Mean & SD & \\
\hline $\operatorname{Male}^{\mathrm{a}}(\mathrm{n}, \%)^{\mathrm{a}}$ & 16 & 64 & 9 & 56.52 & 0.5966 \\
\hline Female $^{\mathrm{a}}(\mathrm{n}, \%)$ & 13 & 36 & 10 & 43.48 & \\
\hline $\operatorname{Age}^{\mathrm{b}}$ (year) & 5.78 & 0.46 & 5.70 & 0.45 & 0.5665 \\
\hline Past NICU admissions ${ }^{\mathrm{c}}(\mathrm{n}, \%)$ & 0 & 0 & 4.00 & 17.39 & 0.0455 \\
\hline Past hospitalizations ${ }^{\mathrm{d}}$ (times) & 0.20 & 0.41 & 0.57 & 0.90 & 0.1216 \\
\hline Past surgeries ${ }^{\mathrm{d}}$ (times) & 0.04 & 0.20 & 0.26 & 0.69 & 0.1336 \\
\hline Past immunizations ${ }^{\mathrm{d}}$ (times) & 27.68 & 5.17 & 28.83 & 6.04 & 0.3307 \\
\hline Past injection ${ }^{\mathrm{d}}$ (times) & 2.12 & 2.65 & 2.30 & 6.27 & 0.1988 \\
\hline Influenza vaccinations during this season ${ }^{\mathrm{d}}$ (times) & 1.16 & 0.37 & 1.22 & 0.42 & 0.6253 \\
\hline Elder siblings who attended ${ }^{\mathrm{d}}$ (persons) & 0.24 & 0.44 & 0.22 & 0.42 & 0.8650 \\
\hline Younger siblings who attended ${ }^{\mathrm{d}}$ (persons) & 0.52 & 0.59 & 0.43 & 0.51 & 0.6782 \\
\hline Minimum sound levels in the treatment room ${ }^{\mathrm{b}}(\mathrm{Hz})$ & 46.01 & 2.71 & 47.13 & 4.09 & 0.2648 \\
\hline Maximum sound levels in the treatment $\operatorname{room}^{\mathrm{d}}(\mathrm{Hz})$ & 47.46 & 3.13 & 47.95 & 4.20 & 0.9236 \\
\hline Minimum sound levels in the waiting $\operatorname{room}^{\mathrm{d}}(\mathrm{Hz})$ & 52.28 & 4.59 & 53.55 & 4.25 & 0.2043 \\
\hline Maximum sound levels in the waiting $\operatorname{room}^{\mathrm{b}}(\mathrm{Hz})$ & 57.87 & 5.81 & 60.70 & 6.10 & 0.1097 \\
\hline Room temperature ${ }^{\mathrm{d}}\left({ }^{\circ} \mathrm{C}\right)$ & 23.95 & 1.36 & 23.88 & 1.32 & 0.6052 \\
\hline Room humidity ${ }^{\mathrm{b}}(\%)$ & 58.61 & 7.22 & 56.00 & 6.58 & 0.2068 \\
\hline Time to initiate the study ${ }^{\mathrm{d}}$ (hours) & 14.00 & 2.35 & 14.65 & 2.25 & 0.2954 \\
\hline Time to period from the initiation to immunization ${ }^{\mathrm{d}}$ (minutes) & 13.40 & 3.26 & 12.44 & 2.29 & 0.3218 \\
\hline Time to duration ${ }^{\mathrm{d}}$ (minutes) & 26.25 & 3.59 & 25.61 & 2.31 & 0.6647 \\
\hline
\end{tabular}

${ }^{\mathrm{a}}$ Chi square test $\mathrm{P}<0.05$, ${ }^{\mathrm{b}}$ Unpaired $\mathrm{t}$-test $\mathrm{P}<0.05$, ${ }^{\mathrm{c}}$ Fisher's exact test $\mathrm{P}<0.05$, ${ }^{\mathrm{d}}$ Wilcoxon rank sum test $\mathrm{P}<0.05$. 


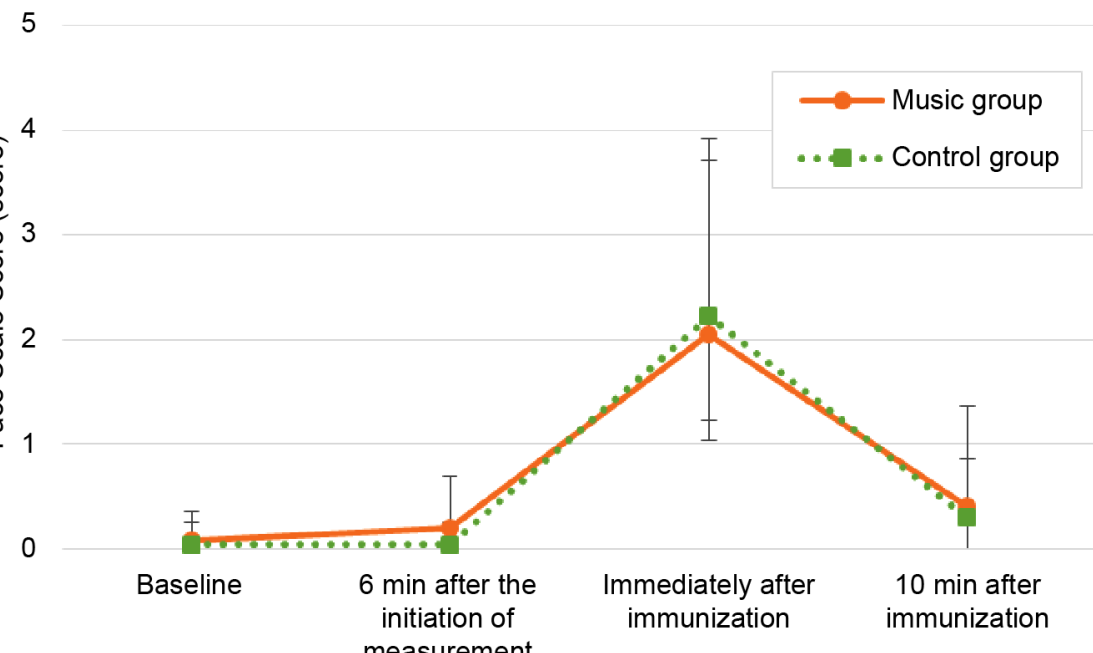

Figure 3. Comparison of Face Scale Scores between music group and control group. At the all points, there were no significant score. Wilcoxon rank sum test $\mathrm{P}<0.05$.

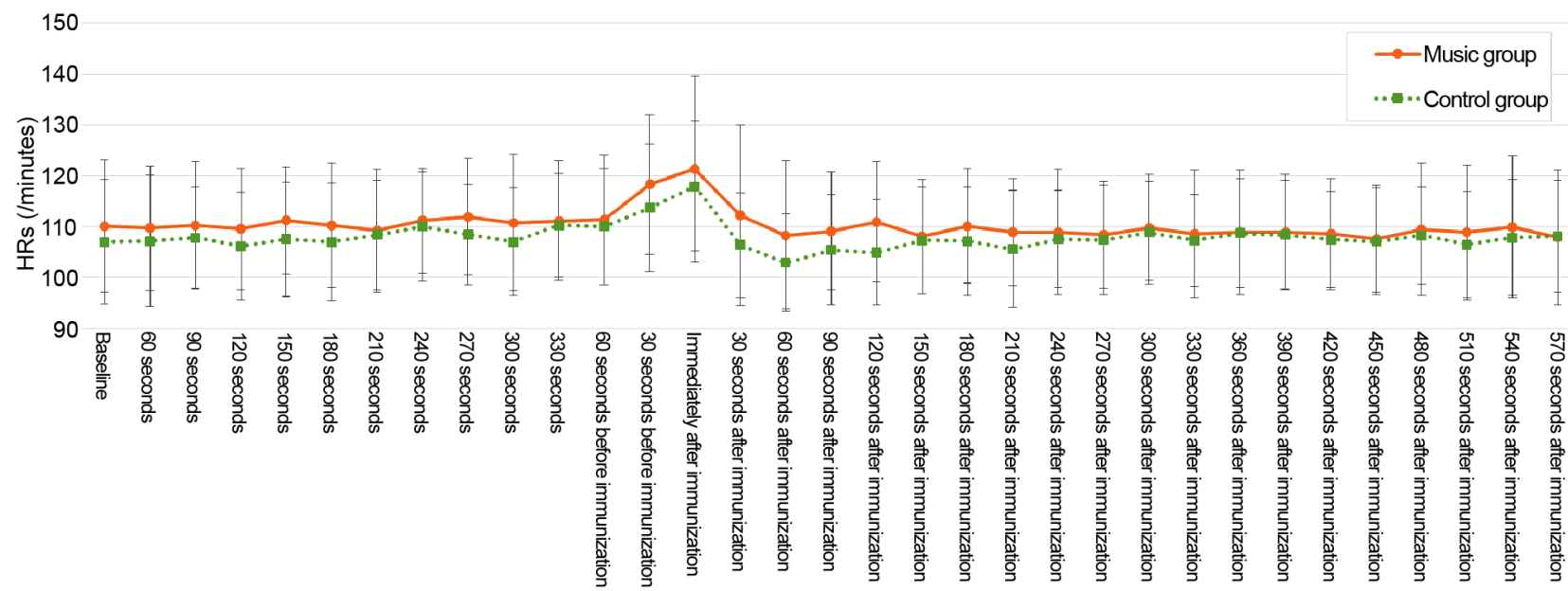

Figure 4. Comparison of HRs between music group and control group. At the all points, there were no significant differences between the Music and Control groups in the HR. Unpaired t-test or Wilcoxon rank sum test $\mathrm{P}<0.05$.

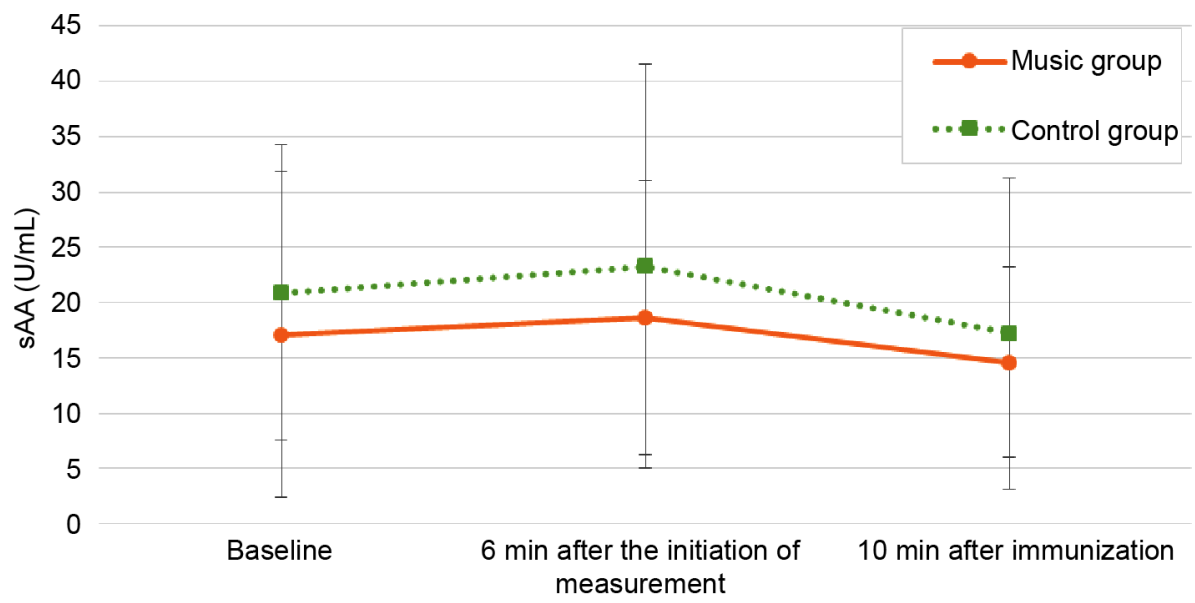

Figure 5. Comparison of sAA between music group and control group. At the all points, there were no significant differences between the Music and control groups in the sAA. Wilcoxon rank sum test $\mathrm{P}<0.05$. 


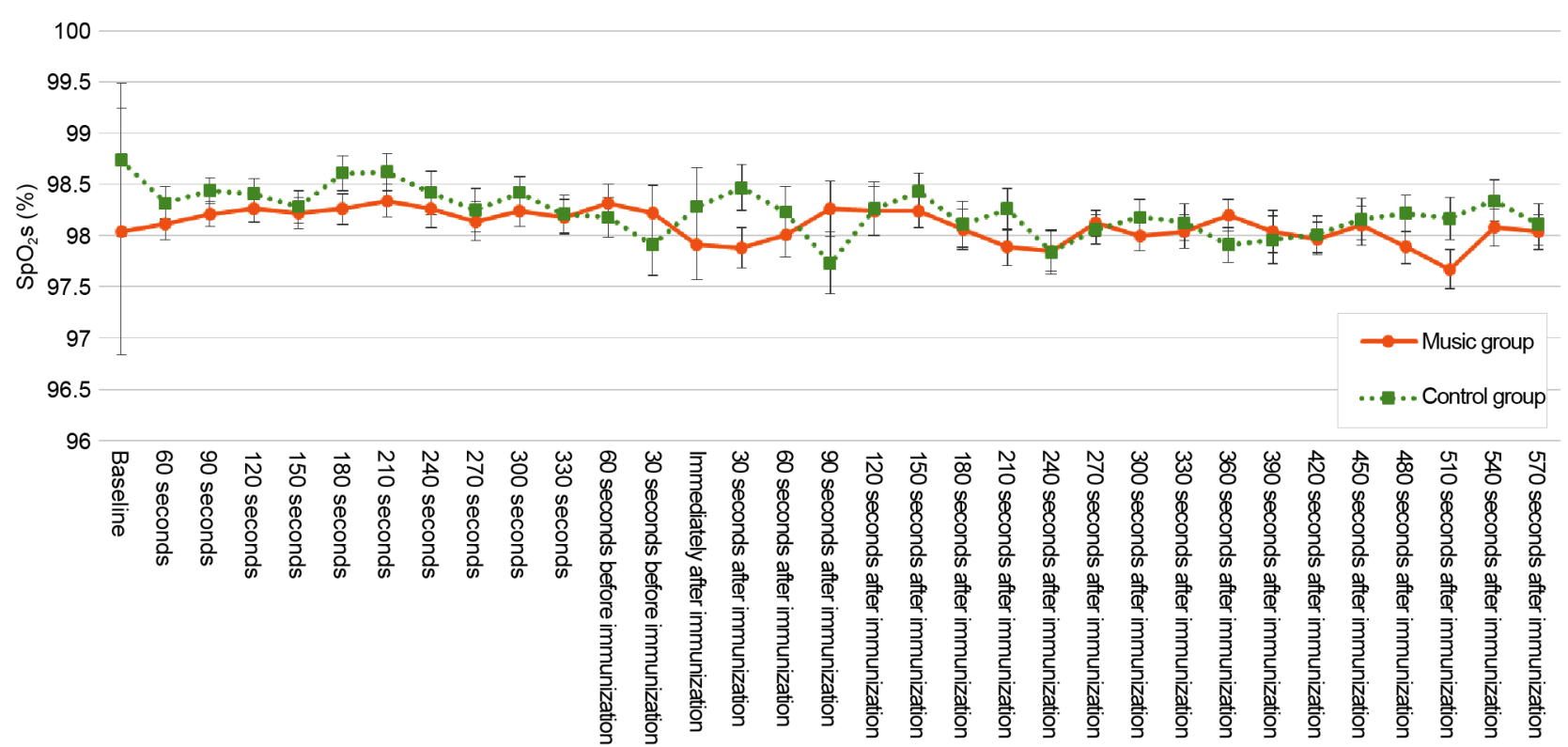

Figure 6. Comparison of $\mathrm{SpO}_{2} \mathrm{~s}$ between music group and control group. The $\mathrm{SpO}_{2}$ level was significantly higher at baseline and 30 seconds after immunization in the Control group than in the Music groups. Analysis of covariance $\mathrm{P}<0.05$.

between the Music and Control groups immediately after immunization. Only the $\mathrm{SpO}_{2}$ level was significantly higher at 30 seconds after immunization in the Control group than in the Music groups $(\mathrm{P}=0.0489)$. The HR did not markedly vary between the groups at any of the 19 points from 30 seconds to 10 minutes after immunization. There were no significant differences in the Face Scale score or sAA level between them at 10 minutes after immunization.

\subsection{Comparison of Baseline and Subsequent Values in Each Group}

\subsubsection{Music Group}

There were no significant differences between the baseline $\mathrm{HR}$ and $\mathrm{SpO}_{2}$ level and those measured at any of the 12 points from 1 minute after the initiation of measurement to immediately before immunization. Similarly, there were no significant differences between the baseline Face Scale score and sAA level and those obtained 5 minutes after the initiation of musical intervention (6 minutes after the initiation of measurement).

The Face Scale score and HR immediately after immunization were significantly higher than those at the baseline $(\mathrm{P}<0.05)$. In contrast, the $\mathrm{SpO}_{2}$ level immediately after immunization was not significantly different from the baseline value. There were no significant differences between the baseline $\mathrm{HR}$ and $\mathrm{SpO}_{2}$ level and those measured at any of the 19 points from 30 seconds to 10 minutes after immunization. Similarly, the Face Scale score and sAA level at 10 minutes after immunization were not significantly different from those at the baseline.

\subsubsection{Control Group}

There were no significant differences between the baseline $\mathrm{HR}$ and $\mathrm{SpO}_{2}$ level 
and those measured at any of the 12 points from 1 minute after the initiation of measurement to immediately before immunization. Similarly, there were no significant differences between the baseline Face Scale score and sAA level and those obtained 6 minutes after the initiation of measurement.

The Face Scale score and HR immediately after immunization were significantly higher than those at the baseline $(\mathrm{P}<0.05)$, while the $\mathrm{SpO}_{2}$ level at immediately after immunization was not markedly different from the baseline value. There were no significant differences between the baseline $\mathrm{HR}$ and $\mathrm{SpO}_{2}$ level and those measured at any of the 19 points from 30 seconds to 10 minutes after immunization. Similarly, the Face Scale score and sAA level at 10 minutes after immunization were not significantly different from the baseline values.

\subsection{History of NICU Admission}

The results were the same when including and excluding 4 preschoolers with a history of NICU admission.

\section{Discussion}

\subsection{Immunization-Related Pain}

In both the Music and Control groups, the Face Scale score and HR markedly increased immediately after immunization, supporting the findings of the previous studies (reporting pain in children receiving immunization, blood sampling, and acupuncture, respectively) [16] [21] [30]. Thus, influenza immunization was painful for the children.

\subsection{Effect of Music to Reduce Immunization-Related Pain}

There were no significant differences between the Music and Control groups in the Face Scale score, $\mathrm{HR}$, or $\mathrm{SpO}_{2}$ level at any point, excluding the third item measured 30 seconds after immunization, indicating that music was not effective to reduce immunization-related pain.

This result may have been due to a low level of pain, in addition to the small sample size. For example, in a previous study, music from speakers effectively reduced pain in children, including preschoolers, undergoing blood sampling [13]. As their HRs and Face Scale scores immediately after blood sampling were higher than the values in the present study [13], it is likely that the procedure was more painful than immunization. The sample size of another study, in which music from headphones reduced immunization-related pain in preschoolers was 200 [19], while those of 2 studies that did not achieve such effects were 99 and 62, respectively [21] [22]. In contrast, the sample size of the present study was 48 , which is even smaller than the latter. This suggests that sufficient pain-relieving effects were not achieved using music, as the level of immunization-related pain was lower than that due to blood sampling, and the sample size was insufficient. 
The sAA level did not markedly vary between the Music and Control groups at any point. Furthermore, in both groups, it did not show a significant difference from the baseline value before/after immunization, revealing that music did not reduce immunization-related stress. As a factor associated with this, the high number of past immunizations among the subjects $(28.83 \pm 6.04)$, which had possibly made this procedure familiar to them, should be noted. In a previous study involving 11 children aged 4 - 15, their sAA levels during blood sampling were markedly higher than those after it and the standard values, indicating that the procedure was stressful for them [30]. In contrast, as the Control group's sAA level did not markedly change after the baseline in the present study, immunization may have been less stressful, making it difficult to achieve clear pain-relieving effects. In short, a stress level lower than that when undergoing blood sampling, as well as an insufficient sample size, may have prevented music from effectively reducing immunization-related stress. It is also undeniable that such stress was not accurately evaluated, as sAA measurement was not performed immediately after immunization.

\subsection{Future Challenges}

As study limitations, both the sample size and measurement variables were insufficient. Among previous studies using scales to measure distress, 2, in which music reduced immunization-related pain in preschoolers, used the Child-Adult Medical Procedure Interaction Scale-Revised (CAMPIS-R) and Observational Scale of Behavioral Distress (OSBD), respectively [21] [34]. These scales are multi-item objective indices with sufficient reliability and validity. Therefore, it may be necessary to further examine the pain-relieving effect of music using them, with immunization-related distress incorporated.

Furthermore, as topical local anesthetics (EMLA CREAM) have also been reported to reduce immunization-related pain [37], intervention methods combining multiple approaches, such as these drugs and music that may show pain-relieving effects, should also be considered to reduce immunization-related pain and distress in preschoolers.

\section{Conclusion}

Influenza immunization was painful for the preschoolers. However, music from speakers did not reduce their immunization-related pain or stress, represented by their Face Scale scores, HRs, and $\mathrm{SpO}_{2}$ and sAA levels. Therefore, it may be necessary to further examine the effect of music to reduce immunization-related distress in preschoolers.

\section{Acknowledgements}

The authors would like to express their sincere gratitude to the children and their parents who cooperated with the study. They also cordially thank staff of the study clinic for their willing cooperation. 


\section{References}

[1] Vaccination Schedule Recommended by the Japan Pediatrics Society. https://www.jpeds.or.jp/uploads/files/vaccine_schedule.pdf

[2] Routine/Voluntary Immunization Schedule in Japan. http://www.nih.go.jp/niid/images/vaccine/schedule/2015/JP20150518.pdf

[3] Schechter, N.L., Zempsky, W.T., Cohen, L.L., McGrath, P.J., McMurtry, C.M. and Bright, N.S. (2007) Pain Reduction during Pediatric Immunizations: Evidence-Based Review and Recommendations. Pediatrics, 119, e1184-1198. https://doi.org/10.1542/peds.2006-1107

[4] Pate, J.T., Blount, R.L., Cohen, L.L. and Smith, A.J. (1996) Childhood Medical Temperament as Predictors of Adult Functioning in Medical Situations. Children's Health Care, 25, 281-298. https://doi.org/10.1207/s15326888chc2504_4

[5] Birnie, K.A., Chambers, C.T., Taddio, A., McMurtry, C.M., Noel, M., Pillai Riddell, R. and Shah, V. (2015) Psychological Interventions for Vaccine Injections in Children and Adolescents: Systematic Review of Randomized and Quasi-Randomized Controlled Trials. The Clinical Journal of Pain, 31, S72-S89. https://doi.org/10.1097/AJP.0000000000000265

[6] Taddio, A., Ilersich, A.L., Ipp, M., Kikuta, A. and Shah, V. (2009) Physical Interventions and Injection Techniques for Reducing Injection Pain during Routine Childhood Immunizations: Systematic Review of Randomized Controlled Trials and Quasi-Randomized Controlled Trials. Clinical Journal of Pain, 31, S48-S76.

[7] Shah, V., Taddio, A. and Rieder, M.J. (2009) Effectiveness and Tolerability of Pharmacologic and Combined Interventions for Reducing Injection Pain during Routine Childhood Immunizations: Systematic Review and Meta-Analyses. Clinical Therapeutics, 31, S104-S151. https://doi.org/10.1016/j.clinthera.2009.08.001

[8] Schechter, N.L., Zempsky, W.T., Cohen, L.L., McGrath, P.J., McMurtry, C.M. and Bright, N.S. (2007) Pain Reduction during Pediatric Immunizations: Evidence-Based Review and Recommendations. Pediatrics, 119, e1184-e1198.

https://doi.org/10.1542/peds.2006-1107

[9] Chambers, C.T., Taddio, A., Uman, L.S. and McMutry, C.M. (2009) Psychological Interventions for Reducing Pain and Distress during Routine Childhood Immunizations: A Systematic Review. Clinical Therapeutics, 31, S77-S103.

https://doi.org/10.1016/j.clinthera.2009.07.023

[10] Eden, L.M., Macintosh, J.L.B., Luthy, K.E. and Beckstrand, R.L. (2016) Minimizing Pain during Childhood Vaccination Injections: Improving Adherence to Vaccination Shedules. http://jur.byu.edu/?p=20354

[11] Klassen, J.A., Liang, Y., Tjosvold, L., Klassen, T.P. and Hartling, L. (2008) Music for Pain and Anxiety in Children Undergoing Medical Procedures: A Systematic Review of Randomized Controlled Trials. Ambulatory Pediatrics, 8, 117-128. https://doi.org/10.1016/j.ambp.2007.12.005

[12] Bo, L.K. and Callaghan, P. (2000) Soothing Pain-Elicited Distress in Chinese Neonates. Pediatrics, 105, E49. https://doi.org/10.1542/peds.105.4.e49

[13] Hartling, L., Newton, A.S., Liang, Y., Jou, H., Hewson, K., Klassen, T.P. and Curtis, S. (2013) Music to Reduce Pain and Distress in the Pediatric Emergency Department: A Randomized Clinical Trial. JAMA Pediatric, 167, 826-835. https://doi.org/10.1001/jamapediatrics.2013.200

[14] Balan, R., Bavdekar, S.B. and Jadhav, S. (2009) Can Indian Classical Instrumental Music Reduce Pain Felt during Venipuncture? Indian Journal of Pediatrics, 76, 
469-473. https://doi.org/10.1007/s12098-009-0089-y

[15] Anastasi, F., Caprilli, S., Grotto, R.P., Scollo, A.M. and Messeri, A. (2007) Interactive Music as a Treatment for Pain and Stress in Children during Venipuncture: A Randomized Prospective Study. Journal of Developmental \& Behavioral Pediatrics, 28, 399-403. https://doi.org/10.1097/DBP.0b013e31811ff8a7

[16] Yu, H., Liu, Y., Li, S. and Ma, X. (2009) Effects of Music on Anxiety and Pain in Children with Cerebral Palsy Receiving Acupuncture: A Randomized Controlled Trial. International Journal of Nursing Studies, 46, 1423-1430. https://doi.org/10.1016/j.ijnurstu.2009.05.007

[17] Ozdemir, F.K. and Tufekci, F.G. (2012) The Effect of Using Musical Mobiles on Reducing Pain in Infants during Vaccination. Journal of Research in Medical Sciences, 17, 662-667.

[18] Sundar, S., Ramesh, B., Dixit, P.B., Venkatesh, S., Das, P. and Gunasekaran, D. (2016) Live Music Therapy as an Active Focus of Attention for Pain and Behavioral Symptoms of Distress during Pediatric Immunization. Clinical Pediatrics, 55, 745-748. https://doi.org/10.1177/0009922815610613

[19] Fowler-Kerry, S. and Lander, J.R. (1987) Management of Injection Pain in Children. Pain, 30, 169-175. https://doi.org/10.1016/0304-3959(87)91072-4

[20] Kristjansdottir, O. and Kristjansdottir, G. (2011) Randomized Clinical Trial of Musical Distraction with and without Headphones for Adolescents' Immunization Pain. Scandinavian Journal of Caring Sciences, 25, 19-26. https://doi.org/10.1111/j.1471-6712.2010.00784.x

[21] Megel, M.E., Houser, C.W. and Gleaves, L.S. (1998) Children's Responses to Immunizations: Lullabies as a Distraction. Issues in Comprehensive Pediatric Nursing 21, 129-145. https://doi.org/10.1080/014608698265456

[22] Noguchi, L.K. (2006) The Effect of Music versus Nonmusic on Behavioral Signs of Distress and Self-Report of Pain in Pediatric Injection Patients. Journal of Music Therapy, 43, 16-38. https://doi.org/10.1093/jmt/43.1.16

[23] Hospitals Providing Music Therapy. http://www.ongakunotomo.co.jp/web_content/onryo_hiroba/pdf/byoin.pdf

[24] Taddio, A., Appleton, M., Bortolussi, R., Chambers, C., Dubey, V., Halperin, S., Hanrahan, A., Ipp, M., Lockett, D., MacDonald, N., Midmer, D., Mousmanis, P., Palda, V., Pielak, K., Riddell, R. P., Rieder, M., Scott, J. and Shah, V. (2010) Reducing the Pain of Childhood Vaccination: An Evidence-Based Clinical Practice Guideline. Canadian Medical Association Journal, 182, E843-E855. https://doi.org/10.1503/cmaj.092048

[25] Ogawa, D., Okamoto, M. and Daitou, M. (2009) The Evaluation of Stress during Dental Treatment of Infant Patients by the Saliva Alpha-Amylase and the Influence of the Mothers. The Japanese Journal of Pediatric Dentistry, 47, 607-614.

[26] Hirakawa, N. (2011) Pain Assessment Scales. Anesthesia 21 Century, 13, 4-10.

[27] Keck, J.F., Gerkensmeyer, J.E., Joyce, B.A. and Schade, J.G. (1996) Reliability and Validity of the Faces and Word Descriptor Scales to Measure Procedural Pain. Journal of Pediatric Nursing, 11, 368-374. https://doi.org/10.1016/S0882-5963(96)80081-9

[28] Iimura, N., Naragino, H., Ninomiya, K., Matsubayashi, T., Michiko, E., Noriko, K., Hitomi, K., Namiko, K., Shinobu, S., Atsuko, S., Mayumi, T., Ayami, N., Hiromi, H. and Makiko, F. (2002) Validity and Reliability of the Face Scale Developed by Wong-Baker in Japan. The Journal of Japanese Society of Child Health Nursing, 11, 21-27. 
[29] Stapelkamp, C., Carter, B., Gordon, J. and Watts, C. (2011) Assessment of Acute Pain in Children: Development of Evidence-Based Guidelines. International Journal of Evidence-Based Healthcare, 9, 39-50. https://doi.org/10.1111/j.1744-1609.2010.00199.x

[30] Ferrara, P., Bottaro, G., Angeletti, S., Gatto, A., Vitelli, O., Battaglia, D., Del, R.M., Ruqqiero, A. and Dicuonzo, G. (2013) Salivary Alpha-Amylase: A New Non-Invasive Biomarker for Assessment of Pain Perception in Epileptic Children. Acta Neurologica Belgica, 113, 279-283. https://doi.org/10.1007/s13760-013-0180-Z

[31] Akdas, O., Basaranoglu, G., Ozdemir, H., Comlekci, M., Erkalp, K. and Saidoglu, L. (2013) The Effects of Valsalva Maneuver on Venipuncture Pain in Children: Comparison to EMLA (Lidocaine-Prilocaine Cream). Irish Journal of Medical Science, 183, 517-520. https://doi.org/10.1007/s11845-013-1037-4

[32] Tanaka, Y. (2008) Techniques for Rapid Analysis of Salivary Stress-Related Components. The Journal of Clinical Laboratory Medicine, 52, 441-449.

[33] Marcia, E.H. (1998) Song Repertoire of Young Children. Music Therapy Perspectives, 16, 37-42. https://doi.org/10.1093/mtp/16.1.37

[34] Yinger, O.S. (2016) Music Therapy as Procedural Support for Young Children Undergoing Immunizations: A Randomized Controlled Study. Journal of Music Therapy, 53, 336-363. https://doi.org/10.1093/jmt/thw010

[35] Stouffer, J.W., Shirk, B.J. and Polomano, R.C. (2007) Practice Guidelines for Music Interventions with Hospitalized Pediatric Patients. Journal of Pediatric Nursing, 22, 448-456. https://doi.org/10.1016/j.pedn.2007.04.011

[36] Stevens, B., Johnson, C., Petryshen, P. and Taddio, A. (1996) Premature Infant Pain Profile: Development and Initial Validation. The Clinical Journal of Pain, 12, 13-22. https://doi.org/10.1097/00002508-199603000-00004

[37] Abuelkheir, M., Alsourani, D., Al-Eyadhy, A., Temsah, M.H., Meo, S.A. and Alzamil, F. (2014) EMLA Cream: A Pain-Relieving Strategy for Childhood Vaccination. Journal of International Medical Research, 42, 329-339.

https://doi.org/10.1177/0300060513509473 